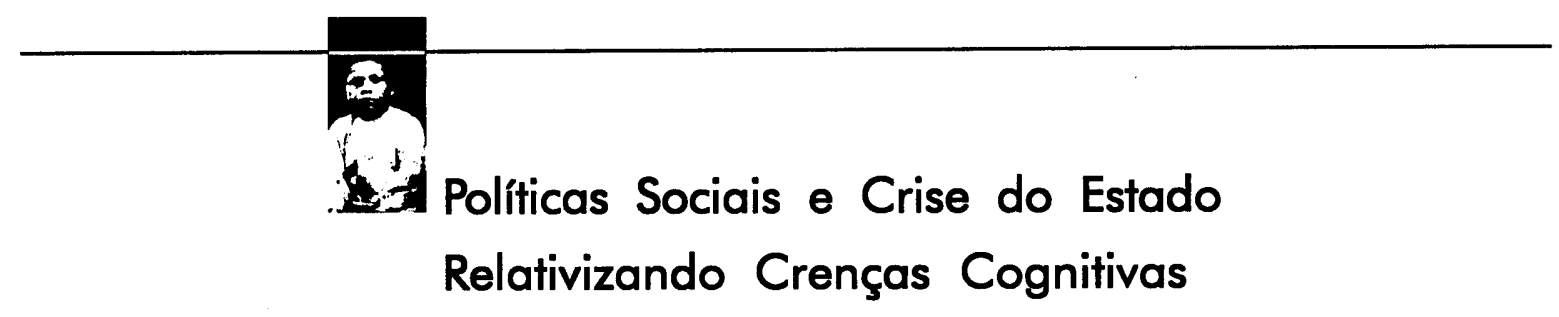

\author{
Nilson do Rosário Costa ${ }^{1}$
}

O trabalho "Política de Saúde no Brasil: a Universalização Tardia como Possibilidade de Construção do Novo", de Elizabeth Barros, faz uma atraente defesa do desenvolvimento institucional e da efetividade das políticas públicas brasileiras de saúde e, indiretamente, das políticas de saneamento, nas décadas de 80 e 90 . Revela a contribuição dos arranjos institucionais e processos decisórios democratizantes na redefinição da agenda da política setorial, ao recortar formas de representação de interesses, e ao assegurar o desenvolvimento incremental da ação governamental. A configuração da política de saúde - e seus efeitos sobre a organização de interesses e indicadores de acesso a bens públicos - é o objeto central do trabalho. A análise desta política relaciona-se ao campo de avaliação da efetividade e utilidade dos sistema de proteção social brasileiro, e à definiçào da agenda social para os anos 90 .

As avaliações das políticas sociais brasileiras apenas residualmente se preocuparam em definir as funções da ação governamental na distribuição de bens sociais. Estas avaliações sustentaram-se em várias e irredutíveis crenças cognitivas. Primeiramente, os estudos questionaram a existência das políticas sociais ao afirmar que metas sociais (educação, saúde pública, habitação e previdência social) foram variáveis secundárias, ou mesmo nulas, nas diretrizes econômicas e nos principais planos e programas adotados pelos governos brasileiros nas décadas pas- sadas. Ratificou-se a interpretação de que a agenda social no Brasil teria ficado reduzida ao reflexo das mudanças econômicas. Identificaram-se os limites estruturais da economia, que impediriam a prática de um programa explícito que sistematizasse e franqueasse o entrosamento à questão social do país, a despeito da forte repercussão da engenharia do "populismo" na análise da formação do Estado brasileiro. Esta interpretação tornouse crença normativa nos anos 70/80, sendo insistentemente retomada nas avaliações do desempenho do Estado como provedor de bens de consumo coletivo. Assumiu-se a hipótese da absoluta inoperância da ação pública no campo das políticas sociais. A literatura avalizou a idéia sobre a ação residual do Estado na reprodução da força de trabalho, comprovável pelo não-aparelhamento das cidades ou baixa oferta de serviços de consumo coletivo.

Uma segunda orientação teórica centrouse na avaliação de procedimentos decisórios do Estado nacional brasileiro. A avaliação das políticas públicas distributivas abandonava a matriz teórica anterior, vinculada à idéia de resíduo e escassez, para reconhecer que o capitalismo brasileiro teve que viabilizar rotinas de políticas sociais. Seria por intermédio delas que teria se efetivado, no caso da infraestrutura urbana, a união entre as demandas sociais e o interesse concreto da ordem capitalista, representado pelas empresas estatais e pelos grupos ligados à construção civil

\footnotetext{
${ }^{1}$ Escola Nacional de Saúde Pública/FIOCRUZ e Instituto de Saúde Coletiva/UFF, Rio de Janeiro e Niterói.
} 
e à oferta de atenção médica. De acordo com esta matriz teórica, a situação de insulamento das tecno-burocracias setoriais teria produzido a instrumentalização das políticas governamentais por meio da lógica dos interesses empresariais, conjugando estatismo e "privatismo".

A centralização decisória comprometeria a capacidade de planejamento e coordenação da ação governamental. A ausência de "pressões de baixo", aliada à fragmentação do aparelho de Estado, produziu os nichos burocráticos autonomizados, com marcada tendência à privatização. As relações simbióticas entre privatização e política social serviram como caracterização genérica da ação governamental do regime burocrático-autoritário:

(i) Pela adoção de critérios de mercado como parâmetros decisivos de comportamento. Ao serem tratados como bens privados no mercado, os benefícios sociais teriam assumido, inexoravelmente, a forma de mercadoria, perdendo sua característica de bens coletivos ou universais;

(ii) Pela transferência da provisão de bens e serviços de natureza social a organizaçōes empresariais privadas, operando no mercado;

(iii) Pela reciclagem do dinheiro público, destinado a programas sociais, no sistema financeiro, impondo a necessidade de remuneração em níveis de mercado;

(iv) Pela particularização de programas sociais, isto é, sua captura por interesses particulares de grupos específicos, tornando-os privilégios corporativos ou ocupacionais, quando não instrumentos de acumulação de capital. No último caso, o beneficiário maior passaria a ser o provedor do serviço sob a forma de mercadoria, e não aquele que demandou bens e serviços.

Uma terceira linha de análise da política social foi difundida na segunda metade da década de 80 , no interior do debate sobre a transição democrática, com o propósito de responder ao dramático quadro social produzido pelo regime autoritário. Contemplou a pretensão de trazer para o centro do debate a alteração do padrão de atuação do Estado na área social nas duas décadas anteriores. Propunha-se a reorganização do aparelho administrativo de prestação de serviços sociais, supostamente desorganizado pela centralização decisória e operacional, fragmentado institucionalmente em diversas agências competitivas, que se mostravam ineficazes e ineficientes, apesar da quantidade e da abrangência dos programas sociais existentes; defendia-se a descentralização decisória e executiva, maior participação comunitária na definição, gestão e controle dos programas, e a ampliação de programas emergenciais para fazer face às situações críticas de desemprego e fome geradas pela crise econômica.

Ratificava-se o diagnóstico sobre a regressividade das políticas sociais pela vinculação de fundos e pelo baixo comprometimento do orçamento fiscal; sob o ponto de vista organizacional, concluía-se que o aparetho administrativo seria centralizador, fragmentado, dispersivo de recursos, opaco e clientelista. Identificavam-se limitações na definição de prioridades e alocação de recursos, por força das exigências de investimentos produtivos, em contraposição aos gastos não produtivos de natureza social, e constrangimentos criados pelos mecanismos de implementação de políticas, que obstruiriam o acesso dos pobres aos serviços providos pelo Estado. Como resultado dessa ineficácia institucional, a política social teria contribuído para que se avolumasse um conjunto de programas mergulhados em profunda crise financeira, conduzidos por uma fantástica máquina burocrática centralizada, mal paga e ineficiente, produtora de políticas desiguais e socialmente injustas.

Esta apreciação ratificava a avaliação sobre o gasto social realizada pelo Banco Mundial em 1988. As políticas sociais brasileiras seriam, para o Banco Mundial, ineficientes, por subsidiarem programas que não atingem os 
pobres, pela apropriação desses altos subsídios primariamente pelas classe médias e pelos ricos, e devido ao fracasso em alcançar os mais necessitados. A partir desta orientação, o Banco Mundial sugeriu uma pauta de quatro pontos para a reforma da política social:

(i) Aumentar a "focalizaçào do gasto público, incluindo a cobrança dos que podem pagar por certos benefícios e o estímulo à oferta pelo setor privado de certos serviços;

(ii) Descentralizar a execução dos programas sociais para estados e governos locais;

(iii) Eliminar qualquer vinculação de fundos e contribuição sobre folha de pagamento;

(iv) Fortalecer o papel do governo federal no controle de qualidade e provisão de informação ao consumidor (World Bank, 1988).

Apesar das afirmações categóricas, que seriam transformadas em crença cognitiva para a avaliação das políticas sociais até início dos anos 90 , esta última matriz de análise não recorreu a pesquisas específicas que comprovassem a situação de regressividade, ineficiência e mistargeting.

Esses diagnósticos sobre a inoperância e regressividade das instituiçôes e políticas sociais foram reificados durante os anos 80 pela difusão das orientações normativas do ajuste estrutural, e pelo debate doméstico sobre a crise do Estado desenvolvimentista. Enfatizou-se, então, a desarticulação administrativa, a perda de capacidade de planejamento e o sentimento generalizado de ingovernabilidade.

Para Fiori, por exemplo, a presença do Estado como epicentro desse quadro de crise explicava-se "na medida que (o Estado) condensa, em sua desarticulação e impotência atuais, contradições embutidas em compromisso fundante que foram dribladas, através de décadas, pela possibilidade de crescimento econômico continuado e exercício autoritário incontestável de poder" (Fiori, 1989, p. 105). A desaceleração do crescimento da economia em alguns anos da década teria afetado "brutalmente" o volume de recursos e a ca- pacidade de gastos, levando ao esgotamento "o limite da eficácia possível" do Estado desenvolvimentista. Esta leitura constituiu um álibi teoricamente refinado para comprovar as teses da crise fiscal e da estagnação dos investimentos públicos na segunda metade da clécada de 80.

As análises, ainda sem dispor de indicadores consistentes sobre os efeitos do cenário da transição sobre as engenharias institucionais e suas arenas, retornaram às teses de estagnação e ao paradigma da escassez. A crise do financiamento público da segunda metade dos anos 80 teria dado origem à paralisia dos investimentos sociais e ao agravamento dos indicadores sociais. Estas conclusões tiveram que ser relativizadas no início dos anos 90, quando os balanços mais sistemáticos sobre o desempenho de algumas políticas governamentais, ancoradas em contribuições sociais específicas, revelavam resultados redistributivos $\mathrm{e}$ incrementais do gasto social brasileiro. Analisando retrospectivamente a clécada, Wilmar Faria assinalou, como paradoxo, o que os balanços de políticas específicas há anos afirmavam: "os indicadores sociais não pioraram ao longo da década, havendo mesmo evidências de que uma melhora, ainda que tímida, tenha ocorrido, muito embora os níveis atingidos estejam longe de ser satisfatórios" (Faria, 1992, p. 111)

Utilizando dados abrangentes das PNADs de 1981 e 1989, analisados por Silva (1992), constataram-se melhorias nos indicadores de nutrição, nas condições dos domicílios, nos indicadores educacionais, além de avanços nos indicadores de oferta no âmbito do saneamento e da atenção à saúde.

As razōes desse avanço, talvez paradoxal numa década marcada pela instabilidade e pela crise, são várias, dependendo do indicador considerado: efeitos de longo prazo em alguns casos, diminuição da pressão demográfica em outros. "Estou convencido. contudo, que a forte mobilização política que também caracterizou a década, associada aos 
avanços na organização popular e à reiteração de eleições democráticas e livres explicam, por caminhos diversos, grande parte desses avanços". (Faria, ibid.) (grifos no original)

A conseqüência lógica dessas constatações foi a negação das teses, difundidas pelo próprio Faria anos antes, sobre o "conjunto de programas sociais" do país que, na década de 80, estariam "mergulhados em profunda crise financeira, conduzidos por uma fantástica máquina burocrática centralizada, mal paga e ineficiente, produtora de políticas desiguais e socialmente injustas" (Castro \& Faria, 1989)

Alterando substantivamente o seu julgamento sobre as políticas sociais, Faria reconheceu que "esse resultado tem, a meu juízo, considerável importância na presente conjuntura, marcada, por um lado, pelo indiscriminado ataque neoliberal à presença do Estado e, por outro, pela quase completa desorganização dos serviços públicos dependentes do governo federal". Essa análise indica que "é preciso caminhar devagar com o andor quando o santo é de barro: como as necessidades básicas elementares, especialmente para as camadas mais pobres da população, são atendidas pelos serviços públicos, é preciso ter presente que se a situação é ruim com os serviços sociais de caráter público, em virtude de sua precariedade e ineficiência, muito pior seria a situação sem eles. Esses serviços oferecem à população pobre uma 'safety net'. Sua desorganização ou mesmo destruição, especialmente num contexto de crise, pode ter conseqüências graves" (Faria, idem, p. 112) (grifos no original).

Este apelo à cautela não foi de todo suficiente para a reavaliação das leituras reducionistas que qualificaram, de modo bastante negativo, o desempenho do gasto social, enquanto reflexo deformado da inconsistência institucional e fiscal do Estado brasileiro no anos 80. Para estas leituras, a política social só teria sentido se integrada no centro da política econômica.

Esta conclusão, que tem orientado a dis- cussào dos anos 90 sobre a crise do Estado, congelou a hipótese de que o financiamento da política social estaria irremediavelmente comprometido pela crise financeira que atingiu a economia brasileira em seu conjunto. As características estruturais da crise tornaram inconsistentes as soluções setoriais que não fizessem parte da solução macroeconômica.

Nestes termos, alternativas e proposições para o financiamento de setores da área setorial só seriam viáveis através de uma nova engenharia de políticas públicas, que propusesse soluções, no curto, médio e longo prazo, para os problemas da reordenação fiscal, reorganização da dívida pública, estabilização monetária e retomada do desenvolvimento.

Estas leituras atualizaram, numa linguagem mais consistente, as teses estruturalistas, ao desconsiderarem por completo as dinâmicas institucionais das políticas setoriais específicas que, a despeito das igualmente pessimistas e sombrias previsões acerca do desempenho da economia brasileira nos anos 80 , apresentaram uma performance paradoxal. Observou-se, ao contrário, que a configuração das políticas específicas de saúde e saneamento não obedeceu ao diagnóstico da estagnação e paralisia das políticas em escala nacional. Os exemplos referidos no trabalho de Faria ratificam esta percepção, ao revelar que tradições organizacionais, arranjos decisórios e culturas técnicas contribuíram para a definição da agenda substantiva das políticas públicas, recortando a forma de representação de interesses, e viabilizando o desenvolvimento incremental da ação governamental. Arenas de políticas específicas instituíram estruturas e processos políticos característicos, referidos ao poder da legitimidade cognitiva, e a relações entre grupos de interesses que atenuaram ou mediaram determinações estruturais mais evidentes.

Neste sentido, é que sublinhou-se, da perspectiva da avaliação da engenharia institucional do saneamento, que as alocações financeiras para o setor não foram totalmente 
restringidas por constrangimentos fiscais, em especial na segunda metade dos anos 80: apresentaram, ao contrário, um saldo extremamente favorável no quadriênio 1980-1983, com um investimento médio de 1,438 bilhão de dólares. Entre os anos 1985-89 registrouse um novo e expressivo crescimento nos investimentos - em média 1,401 bilhão de dólares -, em parte devido aos impulsos incrementais assegurados pela agenda da Nova República (1985-89), mesmo com a imposição ao setor de saneamento de uma violenta indefinição institucional (Costa, 1996).

As análises sobre a política de saneamento têm ratificado que o arranjo institucional dos anos 80 tornou positiva a aglutinação de serviços em escala estadual, associada a uma contabilização mais uniforme de desempenho, o que seria impossivel em um modelo atomizado, dado o estágio de capacitação técnica da maioria dos municípios. A estabilidade institucional da política pública para o saneamento assegurada pelo PLANASA teria favorecido:

(i) A capacitação técnica das equipes, com a disseminação, para a maioria dos sistemas operados, de procedimentos tecnológicos até então restritos aos grandes centros;

(ii) O domínio sobre sistemas interligados, especialmente nas "conturbações" onde foram integrados múltiplos serviços locais;

(iii) $\mathrm{O}$ adequado gerenciamento das grandes ofertas de água, permitindo o planejamento e o aproveitamento racional de mananciais em escala regional;

(iv) O gerenciamento de grandes complexos de tratamento de esgoto;

(v) O controle da qualidade da água, principalmente no que se refere à disseminação de parâmetros e procedimentos de monitoramento normalizados; medição e cobrança dos serviços prestados, a despeito das deficiências de micromedição dos serviços;

(vi) Uma tecnologia de controle de perdas, que registrou avanços expressivos, apesar de nào terem sido implementadas as medidas necessárias para sua efetivação, e

(vii) A mobilização e a organização setorial, através de atribuição de status público às organizações de interesses que incidem sobre a área, como as entidades ABES, ASSEMAE, AESBE, ASFAMAS e os sindicatos de trabalhadores.

Esta complexidade organizacional, cognitiva e de intermediação de interesses torna explicável o crescimento, na década "perdida" de 80 , da oferta de serviços de saneamento (particularmente do fornecimento de água) para segmentos expressivos da população de todos os estratos de renda.

Pode-se ratificar as conclusões da autora quando afirma que os indicadores mais comuns das condições de saúde (mortalidade infantil tardia, mortalidade por doenças infecciosas e parasitárias, incidência de diarréias, entre outros) evidenciaram progressos que refletiram o impacto do expressivo investimento em infra-estrutura realizados na área de saneamento básico. Esses progressos dos indicadores ocorreram em todas as unidades federadas, ainda que a intensidade tenha sido bastante diferenciada.

No âmbito da saúde o resultado intencional das inovações institucionais da década de 80 foi a ampliação do direito à atenção médica para um universo de beneficiários extremamente diversificado. As mudanças na política de saúde incorporaram de forma "massiva" a "população não-contribuinte" ao mercado consumidor de cuidados médicos, rompendo com o modelo restrito do período corporativo. As crenças científicas associadas ao diagnóstico do "privativismo" e da futilidade das políticas sociais impediram-nos de avaliar os mais elementares efeitos redistributivos provocados pela incorporação dos estratos sociais mais pobres ao consumo de atenção médica e hospitalar. O atrelamento da análise à lógica da subordinação da política social à acumulação, comprovável pelo provimento privado de serviços, que se manteve como 
âncora do sistema, dificultava perceber a fragilidade da lógica da mercantilização da atenção médica. O acesso das populações aos serviços não se subordinou à lógica do mercado.

As mudanças nas políticas governamentais desta conjuntura implementaram, efetivamente, uma agenda de ampliação da eqüidade e justiça social, ainda que tenham adiado a definição sobre que fonte de recursos financiaria esta ampliação de clientelas. Assim, a articulação público/privado, amparada pelo Fundo Previdenciário, sustentou a dramática expansão da oferta de serviços (leitos hospitalares), de modo a responder ao aumento abrupto nas internações, que passam de 2.802.051, em 1970 (3,01 por 100 hab.), para 11.753.451, em 1980 (9,88 por 100 hab.). Esta salto quantitativo na oferta de serviços em todos os níveis de complexidade fragiliza os argumentos que definiram a política de saúde como residual nessas décadas.

A agenda da saúde da Constituição de 1988 e as leis e portarias complementares ampliaram as engenharias institucionais da política de saúde, possibilitando a formulação de diretrizes institucionais eficazes, que podem superar a sua frágil e fragmentada organização sistêmica.

O setor saúde, desde a Constituição de 1988, como sublinha Barros, tem obtido êxito em combinar um dinâmico repertório organizacional com um projeto de massificação do consumo da atenção médica e promoção à saúde. A Carta de 1988 abrigou a idéia da saúde como direito ao acesso universal e igualitário às ações e serviços de promoção, proteção e recuperação (Constituição de 1988, Art. 196); inovou na concepção de orçamento da seguridade social, destinado a financiar as atividades de previdência, assistência social e saúde (Idem, Art. 199), e mantido com recursos da Previdência Social, do Finsocial/Cofins, da Contribuição sobre o Lucro Líquido de Pessoas Jurídicas, etc. A criação do orçamento da seguridade social ratificou a desvincu- lação da contribuição ao acesso a benefícios de saúde e previdência, além do fato da assistência social ter sido elevada à categoria de política constitucionalmente instituída.

Os anos 80 registraram a expansão do comprometimento financeiro e da oferta de serviços como bens públicos que não ratificam os diagnósticos generalizantes acerca dos efeitos das políticas de ajuste neo-liberais ou cla crise do Estado Nacional, aplicados aleatoriamente à América Latina. O Sistema Único de Saúde, criado em 1989, representou a forma institucional de um novo padrão de proteção social. Além da universalização do acesso, o SUS propôs a integralidade da atenção como princípio normativo da organização da ação pública. Outras orientações importantes relacionam-se à reorganização do Estado e à redefinição das funções das três esferas de governo. Alterações nas competências tributárias, na partilha das receitas públicas e nas atribuições das unidades federadas têm se constituído em dimensões de mudança no pacto federativo. Como resultado, a presença dos governos locais na provisão de serviços de saúde tem sido substancialmente fortalecida e o número de estabelecimentos de saúde sob gestão municipal apresentou significativo incremento na década de 80 , com repercussões positivas sobre os indicadores de acesso. Reduziram-se significativamente as diferenças interregionais na oferta de serviços.

O mais importante nesse processo de massificação e ampliação foi a eleição de clientelas sob a condição de cidadâos e não de "pobres". A principal orientação normativa relativa às políticas para os anos 90 parece ser a tentativa de reformar este pressuposto, retirando das políticas específicas qualquer pretensão de intervir na construção de um projeto de cidadania. A conseqüência lógica desse deslocamento é a adoção de critérios de mercado como parâmetro decisivo de organização institucional. Os objetivos finais das políticas serão deslocados para o plano 
secundário; elegendo-se a eficiência econômica, a auto-suficiência financeira e o equilíbrio do orçamento público como metas prioritárias das políticas públicas. Ao serem tratados como bens privados, acessíveis no mercado, os benefícios sociais deverão assumir, segundo esta crença normativa, a forma

\section{Referência Bibliográficas}

CASTRO, M.H.G. \& FARIA, W. (1989) - Política social e consolidação democrática. In: Moura, A.S. (org.) - O Estado e as Políticas puíblicas na transição democrática. Rio de Janeiro: Vértice.

COSTA, N.R. (1996) - Políticas públicas e justiça urbana. Saúde e saneamento na agenda brasileira dos anos 80/90. Tese de Doutorado. FAU/USP, mimeo.

FARIA, W. (1992) - A conjuntura social brasileira. Novos Estudos 33:103-114 de mercadorias, perdendo as suas características de bens públicos. Certamente, prevalecendo estes novos dogmas, realizar-se-ão as profecias que, como vimos, estão "fora de lugar" na década passada, e que qualificam as políticas sociais como instrumentais, seletivas e fúteis.
FIORI, J.L. (1989) - Sobre a crise do Estado brasileiro. Revista de Economia Política 9(3):103-114

SILVA, L.C.E. (1992) - O que mostram os indicadores sobre pobreza na década perdida. Brasilia: IPEA.

WORLD BANK (1988) - Brazil Public Spending on Social Programs: Issues and Options, Vol. I. Washington: The World Bank. 